\title{
O ENSINO MÉDIO E O ENSINO DA LITERATURA - ANTES DA BNCC
}

\author{
Lauro Roberto do Carmo Figueiral \\ Cássia Beatriz Feleol Silva² \\ Carlos Herique Xavier de Aguiar ${ }^{3}$
}

\section{RESUMO}

A pesquisa partiu das leituras sobre os fundamentos legais para o Ensino Médio (DCNEM, PCNEMs, OCNEM), com alguns enfoques específicos acerca da área de Linguagens, tangente ao conteúdo Literatura, antes da consolidação da Base Nacional Comum Curricular (BNCC). Os documentos legais consultados orientam a construção de currículos e descrevem a estrutura do Ensino Médio. Neste sentido, investigaram-se as abordagens, dentro dessas diretivas, sobre os norteamentos dirigidos ao ensino da obra literária no contexto do componente curricular Língua Portuguesa. A justificativa para este recorte de estudo advém da prática docente do autor deste texto, que experimenta, no seu labor, na faculdade de Letras, disparidades entre a matriz curricular do curso de Licenciatura em Letras, Língua Portuguesa, com o currículo sobre o ensino da Literatura, no Ensino Médio. Outrossim, justifica-se em razão de professores da Língua Portuguesa/Literatura, do Ensino Médio, com muitos anos de trabalho, desconhecerem as matrizes oficiais que fundamentam a sua profissão.

Palavras-chave: Escuela secundaria. Docencia. Literatura.

\section{LITERATURE TEACHING IN HIGH SCHOOL BEFORE THE BNCC}

\section{ABSTRACT}

The starting point for this research was a literature review on the legal foundations for high school education (DCNEM, PCNEMs, OCNEM), focusing on the guidelines for the teaching of Languages, and specifically of Literature content, before the consolidation of the Common National Curricular Base (BNCC). The consulted legal documents guide the construction of curricula and describe the structure of education at high school level. Based on these directives, the investigation concentrated on the approaches about the guidelines directed to the teaching of literary work in the context of the Portuguese language curriculum component. The justification for this study stems from the teaching practice of the author of this text,

1 Doutorado. Professor da Universidade Federal do Oeste do Pará, lotado no Instituto de Ciências da Educação, curso de Letras/Língua Portuguesa, Santarém - PA, Brasil. Orcid iD: https://orcid.org/0000-0002-6971-2706. E-mail: laurocf@yahoo.com.br

2 Aluna do Programa de Letras, do curso de Letras/Língua Portuguesa, da Universidade Federal do Oeste do Pará, Santarém- PA, Brasil. Orcid iD: https://orcid.org/0000-0003-3488971X. E-mail: bfele@outlook.com

3 Aluno do Programa de Letras, curso de Letras/Língua Portuguesa, da Universidade Federal do Oeste do Pará, Santarém- PA, Brasil. Orcid iD: https://orcid.org/0000-0002-8145-3743. Email: felipexavieramv@gmail.com 
who experiences, in his work, in the Faculty of Letters, disparities between the curriculum matrix for the Degree in Letters, Portuguese Language, and the curriculum for the teaching of Literature in high school. Moreover, it is justified because, even after many years of teaching, high school Portuguese/Literature teachers are still unaware of the official matrices that underlie their profession.

Keywords: High School. Teaching. Literature.

\section{EDUCACIÓN MEDIA Y EDUCACIÓN DE LITERATURA - ANTES DE BNCC}

\section{RESUMEN}

La investigación partió de las lecturas sobre los fundamentos legales de la escuela secundaria (DCNEM, PCNEMs, OCNEM), con algunos enfoques específicos sobre el área de idiomas, tangentes al contenido de la literatura, antes de la consolidación de la Base Curricular Nacional Común (BNCC). Los documentos legales consultados guían la construcción de planes de estudio y describen la estructura de la escuela secundaria. En este sentido, investigamos los enfoques, dentro de estas directivas, sobre las pautas dirigidas a la enseñanza del trabajo literario en el contexto del componente curricular de la lengua portuguesa. La justificación de este estudio se deriva de la práctica docente del autor de este texto, que experimenta, en su trabajo, en la Facultad de Letras, disparidades entre la matriz curricular del Grado en Letras, Lengua portuguesa, con el plan de estudios sobre la enseñanza de Literatura, en secundaria. Además, está justificado porque los profesores de Lengua / Literatura portuguesa de la escuela secundaria, con muchos años de trabajo, desconocen las matrices oficiales que subyacen en su profesión.

Palabras clave: Primera palabra. Segunda palabra. Tercera palabra.

\section{INTRODUÇÃO}

Como hipótese principal desta pesquisa, aduz-se que o currículo das faculdades de Letras, a documentação regente da educação básica, e os métodos mais utilizados para o ensino da Literatura, necessitam de ajustamento da formação e da requalificação dos professores. As didáticas e as práticas para a formação de leitores literários para o ensino da Literatura utilizadas tanto nas licenciaturas em Letras/Língua Portuguesa quanto no Ensino Médio devem ser reestruturadas em função das normativas oficiais da Câmara de Educação Básica/Ministério da Educação atinentes ao ensino da língua materna e das suas literaturas.

Para a consecução do presente trabalho, procedeu-se ao levantamento da documentação oficial do Ministério da Educação e 
Cultura para o Ensino Médio, compulsando-se normativas nacionais - Lei de Diretrizes e Bases da Educação (LDB), Diretrizes Curriculares Nacionais para o Ensino Médio (DCNEM), Parâmetros Curriculares Nacionais para O Ensino Médio/Linguagens, Códigos e suas Tecnologias (PCNEM), Orientações Curriculares Nacionais para o Ensino Médio/Linguagens, Códigos e suas Tecnologias (OCNEM), Programa Ensino Médio Inovador (proEMI) -, além de Pareceres e estudos técnicos sobre o Ensino Médio.

Este estudo lastreia-se na observação de que o currículo das licenciaturas em Letras/Língua Portuguesa não contempla com necessária profundidade as orientações normativas e legais para o ensino da Literatura no percurso curricular da formação docente. Entende-se que a compreensão das Resoluções e Pareceres que regem a oferta curricular brasileira para o Ensino Médio contribui sobretudo para a formação docente do licenciando.

Esta investigação, também, é orientada pela observação do autor, no andamento de mais de duas décadas do exercício docente, no ensino superior, na qual identifica-se a timidez de debates nos cursos de licenciatura e pós-graduação em Letras sobre o ensino da Literatura à luz dos documentos oficiais que o regem. Essa conjuntura contribui para que 0 modelo curricular das licenciaturas em Letras apresentem estruturas semelhantes ao percurso curricular do bacharelado, alicerçado na formação de pesquisadores.

O Ensino Médio tem sido margeado por vários documentos legais orientadores, entre resoluções, pareceres e textos complementares. Nesta afirmativa, usou-se o verbo "margear" no sentido de que tais documentos acompanham o Ensino Médio, mas com reduzida interferência para a consolidação deste nível de ensino conforme as diretrizes das LDBs, das DCNEM, dos PCNEMs e das OCNEM. Entre os problemas para a implementação dos documentos divulgados pelas secretarias de educação, no processo de ensino-aprendizagem, apontam-se: excesso de conteúdo e pouca finalidade prática ao direcionamento do exercício pedagógico, embora o escopo deles defina dirigir e sugerir a construção de projetos 
pedagógicos coletivos; ausência de estudos cíclicos sobre eles, de modo que docentes recém-contratados apenas 'ouvem falar' de que os documentos existem; registros em relatórios oficiais de que essas orientações às vezes não chegam aos devidos destinos para debates (BRASIL, MEC. Projeto UNESCO. Edital 7/2014, TOR 8/2014, DCNEM, Projeto UNESCO/CNE 914BRZ1 144). Em que pesem os fatores apontados, as diretrizes e orientações curriculares manifestam $\bigcirc$ empenho do Ministério da Educação em promover o protagonismo dos professores lotados nas unidades escolares a fim de democratizar as informações sobre as construções dos projetos técnico-pedagógicos.

Esse acervo normativo dinamizou orientações pedagógicas atentas a contextualizações (linguística, geográfica, social e cultural) - enfeixando os componentes diversificados do currículo -, e garantiu uma base comum. A parte diversificada, compreendendo as inclinações de cada região, e a base comum nacional, por sua vez, fixaram conteúdos para as redes de ensino erigirem suas grades curriculares. Reitera-se, entretanto, que a implementação de ambas ficou comprometida, tendo em vista o pouco acesso dos docentes à análise desse acervo, em regiões recônditas do país.

Em obediência às perspectivas do programa das diretrizes curriculares, os parâmetros para o Ensino Médio, na área de Linguagens, abarcaram heterogeneidades sociais, culturais, regionais e econômicas, do país. Dessa compreensão, emergiu uma idealização para a construção de projetos pedagógicos centrada na interdisciplinaridade a incentivar projetos escolares de ações conjuntas, envolvendo articulações entre componentes curriculares de diferentes áreas do conhecimento. Contudo, não é comum as licenciaturas formarem professores com educação interdisciplinar. As equipes que redigiram os documentos para $\bigcirc$ Ensino Médio não consideraram essa disparidade impeditiva para $\bigcirc$ aluno secundarista alcançar as competências e habilidades previstas nos documentos orientadores.

Outra idealização verificada nos documentos pedagógicos para o Ensino Médio, de 1996 a 2015, consubstanciou-se na necessidade das 
conexões intrínsecas entre as educações Básica e Superior. Na prática, a organização do Ensino Médio Regular não permitiu opções imediatas do estudante aos cursos superiores. O currículo fixo, sem opções por percursos formativos, e o excesso de componentes curriculares, dificultaram o imediato ingresso a estudos posteriores. Os resultados das próprias análises técnicas promovidas pelo Ministério da Educação apontaram a demasia de conteúdos, além destes manterem-se distantes da realidade dos alunos (BRASIL, MEC. Projeto UNESCO. Edital 7/2014, TOR 8/2014, DCNEM, Projeto UNESCO/CNE 914BRZ1144).

\section{CAPÍTULO I - AS FUNDAMENTAÇÕES LEGAIS PARA O ENSINO MÉDIO - ANTES DA BNCC}

Para compreender o contexto do ensino da Língua Portuguesa e das Literaturas em vernáculo, no Ensino Médio Regular, é necessário ter em conta as reformas que abrangem o sistema educacional no período compreendido entre os anos de 1996, com a entrada em vigor da Lei de $\mathrm{N}^{\circ}$ 9.394/1996 - Lei de Diretrizes e Bases da Educação -, e a Resolução CNE/CEB $N^{\circ} 2 / 2012$, atualização da citada lei.

O Ministério da Educação, por meio de diversas instâncias avaliadoras e geradoras de documentos responsáveis por administrar a educação nacional, objetiva estruturar o percurso curricular do aluno brasileiro tendo em vista as transformações econômicas, políticas e sociais nacionais e internacionais, bem como as inovações metodológicas ocorridas no domínio da educação.

O Ensino Médio não tem cumprido algumas condições básicos exigidas pela LDB/1996, entre elas: falta de correspondência entre os conteúdos ensinados e a sua materialização pela prática; falhas no gerenciamento das diretrizes curriculares pelas Secretarias Estaduais de Ensino em face da sua aplicação pelas escolas; deficiência da organização curricular, que não promove habilidades e competências básicas para o trabalho. Estes complicadores justificaram alguns debates emergenciais que surgiram em relatórios oficiais, conforme se constata: "O Brasil tem um grande desafio na 
área da educação: melhorar a qualidade do Ensino Médio. O governo admite que essa é a etapa que mais precisa melhorar. O Índice da Educação Básica mostrou que o Ensino Médio piorou em 13 estados." (BRASIL, MEC. Projeto UNESCO. Edital 7/2014, TOR 8/2014, DCNEM, Projeto UNESCO/CNE 914BRZ1144, p. 06). No sentido de caracterizar e definir esse estágio educacional, o relatório técnico de 2014 compreende que:

O Ensino Médio, no Brasil, tem se apresentado, ao longo da história da educação brasileira, como o nível de maior complexidade na estruturação de políticas públicas de enfrentamento aos desafios estabelecidos pela sociedade moderna, em decorrência de sua própria natureza enquanto etapa intermediária entre 0 Ensino Fundamental e a Educação Superior e a particularidade de atender a adolescentes, jovens e adultos em suas diferentes expectativas frente à escolarização [...]. (BRASIL, MEC. Projeto UNESCO. Edital 7/2014, TOR 8/2014, DCNEM, Projeto UNESCO/CNE 914BRZ1144, p. 04).

As primeiras bases definidoras e reguladoras do ensino brasileiro apareceram na Constituição República Federativa do Brasil de 1934, garantindo o acesso à escola como um direito de todos, e se referindo a um plano nacional de educação. Desde então, outras orientações legais foram promulgadas, ajustadas às mudanças sociais e econômicas do país. Nas décadas de $1960^{4}$ e 1970, do século passado, o Ensino Médio se consolidou a partir da industrialização na América Latina, quando houve o planejamento de uma matriz curricular profissionalizante. Assim como as atualizações do ensino a partir dos anos 60 até os anos 80 , do último século, foram redigidas considerando o contexto social e econômico, para a formação do cidadão brasileiro, as atenções, nos anos 90, também, se voltaram para as mudanças da atualidade e para o alinhamento da educação brasileira às exigências internacionais. Além disso, por cerca de uma década, dos finais dos anos 1980 aos 1990, a demanda do Ensino Médio ultrapassou $90 \%$ das matrículas em oferta. Entre outros fatores, essa procura ocorreu pela exigência compatível com os novos horizontes do mercado de trabalho. Contudo, a escolarização dos alunos na faixa dos 17 anos demonstrou o quadro brasileiro inferior diante de muitos países,

\footnotetext{
4 A Lei $N^{\circ} 4.024 / 61$ é a primeira Lei de Diretrizes e Bases da Educação Nacional, revogada pela Lei $N^{\circ} 5.692 / 71$, de 11 de agosto de 1971.
}

Revista Exitus, Santarém/PA, Vol. 10, p. 01-32, e020030, 2020. 
incluindo alguns com rendas per capita menores, na América Latina. Essas condições definiram amplas reformas curriculares. Nesse sentido, O MEC empreendeu mudanças em todo o sistema do ensino pré-universitário a fim de modificar as organizações dos sistemas estaduais de ensino.

As diretrizes curriculares nacionais anteriores às de 1996, regulamentadas pela LDB de $N^{\circ} 5.692 / 71$, de 11 de agosto, tinham por meta formar o aluno, no $2^{\circ}$ Grau, para o prosseguimento dos estudos e habilitá-lo para desempenhar uma profissão técnica, além de privilegiar o conteúdo e o acúmulo de informações. A LDB de No 9.394/1996, de 20 de dezembro, por sua vez, definiu, entretanto, outra orientação para o Ensino Médio, tendo por critério, sobretudo, as mudanças de: a) fatores econômicos, propiciados pela ruptura tecnológica, que instauram nova organização de trabalho e variadas relações sociais; b) fatores sociais, pois a dimensão e a diversidade do país exigem contextualização e transversalidade curricular; c) fatores relacionados à expansão ininterrupta da rede pública de ensino relacionada à concepção teórica sobre o papel da escola, na qual é imprescindível o uso de tecnologias.

Para além da memorização de dados, as novas orientações tiveram por objetivo desenvolver a aquisição de conhecimentos básicos para o prosseguimento dos estudos; a formação básica para o mundo do trabalho; e a preparação científica, com vistas ao desenvolvimento do pensamento autônomo e crítico. Pretendeu-se, desse modo, formar um cidadão apto ao exercício da cidadania (LDB Lei No 9.394/1996, Art. 22). Assim, a LDB de 1996 define e regulariza a estrutura da educação brasileira sob os princípios constitucionais consagrados na Constituição de 1988.

A Câmara de Educação Básica (CEB), do Conselho Nacional de Educação (CNE), desde a publicação da LDB/1996, ocupou-se mormente em cumprir a incumbência de deliberar as Diretrizes Curriculares Nacionais. Essas diretrizes caracterizam-se como conjuntos de princípios, critérios e procedimentos a serem observados pelos sistemas de ensino e pelas escolas relativamente à organização, ao planejamento, à execução e à avaliação de cursos e respectivos projetos pedagógicos. Elas foram construídas depois 
de ampla mobilização profissional, e complementadas posteriormente por outros documentos legais, orientadores e caracterizadores dos ciclos de estudos da formação básica. Dentre os textos derivados das DCNEM, aqui abordados, destacam-se: Parâmetros Curriculares Nacionais para o Ensino Médio (PCNEM), Parâmetros Curriculares Nacionais para o Ensino Médio + $(\mathrm{PCNEM}+)$, Orientações Curriculares para o Ensino Médio (OCNEM), e Programa Ensino Médio Inovador (proEMI). Em 2010, a CEB publicou as Diretrizes Curriculares Nacionais Gerais para a Educação Básica (Resolução CNE/CEB No 4/2010), que atualizaram mudanças ocorridas na LDB/1996. As Diretrizes evocadas coligem princípios, fundamentos legais e procedimentos demarcados pelo Conselho Nacional de Educação para encaminhar as políticas públicas educacionais da União, dos Estados, do Distrito Federal e dos Municípios, na elaboração, no planejamento, na implementação e na avaliação das propostas curriculares do sistema educacional e das unidades escolares públicas e privadas, que oferecem o Ensino Médio.

A implementação dos currículos para a Educação Básica é da competência da Secretaria de Educação Básica (SEB) e avaliada pelo Instituto Nacional de Estudos e Pesquisas Educacionais Anísio Teixeira (INEP), ambos órgãos do MEC. A SEB observa os três ciclos educacionais da Educação Básica - Infantil, Fundamental e Médio - a partir da LDB/1996, das Diretrizes Curriculares Nacionais da Educação Básica, do Plano Nacional de Educação (PNE - aprovado pelo Congresso Nacional em 26 de junho de 2014), além da Constituição/1988 e do Estatuto da Criança e do Adolescente (Lei No 8.069/1990, de13 de julho). O INEP, por meio do Sistema de Avaliação da Educação Básica (SAEB), também avalia a qualidade de cada escola da rede nacional de ensino. A contribuição maior desse exame é concorrer para a equidade e a universalização do acesso à escola (políticas públicas). Neste sentido, o índice de Desenvolvimento da Educação Básica (IDEB), criado pelo INEP, em 2007, reúne indicadores importantes para a verificação dos níveis de desempenhos da educação: fluxo escolar e médias de desempenho nas avaliações. Esses indicadores são 
as balizas referenciais para as metas do Plano Nacional da Educação (PNE/MEC).

Após a entrada em vigor da LDB de 1996, o Conselho Nacional de Educação atualizou as Diretrizes Curriculares Nacionais para a Educação Infantil, para os ensinos Fundamental e Médio, e para a Educação de Jovens e Adultos. Essas Diretrizes representaram doutrinas e princípios norteadores para a construção de projetos pedagógicos e componentes curriculares a partir da LDB de 1996 e de mudanças nela ocorridas anos depois. Enquanto formas de organização dos saberes, estas normativas são reavaliadas para a construção de projetos político-pedagógicos das escolas. Essa última importante reforma (LDB/1996) tem recebido modificações quanto à faixa etária da entrada dos alunos na fase inicial dos estudos e consequentemente um reajuste dentro do ciclo do Ensino Fundamental. Ainda, houve a inserção de disciplinas no Ensino Médio, entre outras alterações.

As Diretrizes Curriculares para o Ensino Médio, instituídas pela Resolução CEB $N^{\circ} 3 / 1998$, de 26 de junho, foram as primeiras formulações que estabeleceram as orientações para a implementação da LDB/1996. Os documentos técnicos, posteriormente publicados, usaram como referência a regulamentação, a organização e os princípios norteadores nelas contidos. Essas diretivas constituíram desde logo entendidas como passíveis de alterações. O Parecer No 15/1998, de 01 de junho, que trata dessas diretrizes, foi o primeiro estudo detalhado da nova proposta curricular do Ensino Médio, - qual aponta antecipadamente para contínuas mudanças das diretrizes curriculares nacionais, conforme a citação seguinte:

A implementação destas DCNEM será ao mesmo tempo um processo de ruptura e de transição. Ruptura porque sinaliza para um Ensino Médio significativamente diferente do atual, cuja construção vai requerer mudanças de concepções, valores e práticas, mas cuja concepção fundante está na LDB (p. 95).

O entendimento de ruptura e transição, ou ajustes, também pode ser aplicado para as atuais discussões sobre a nova construção de uma base comum curricular para a Educação Básica. A publicação dos resultados 
preliminares das duas versões da BNCC/Ensino Médio la primeira em 16/09/2015, e a segunda em 03/05/2016) conservam os princípios gerais ditados nas DCNEM/1998 (Resolução CEB Nº 3/1998, de 26 de junho) e nas DCNEM/2012 (Resolução CNE/CEB No 2/2012, de 30 de janeiro), relativamente à organização das Áreas de Ensino. Esta Resolução de 2012 reuniu atualizações 5 , no Artigo $2^{\circ}$, para o Ensino Médio, em compasso com as Diretrizes Curriculares Nacionais Gerais para o Ensino Médio (Resolução No 4/2010, de 13 de julho).

O documento Orientador de 2013, do Programa Ensino Médio Inovador (proEMl/2009), em etapa mais avançada sobre os debates e as conclusões acerca do Ensino Médio, resumiu as propostas das DCNEM:

[...] as dimensões do trabalho, da ciência, da tecnologia e da cultura como eixos integradores entre os conhecimentos de distintas naturezas; o trabalho como princípio educativo; a pesquisa como princípio pedagógico; os direitos humanos como princípio norteador; e a sustentabilidade socioambiental como meta universal (p. 14).

A disposição desses fundamentos orientou a compreensão de que os conhecimentos e os produtos advindos da iniciação científica escolar deveriam dialogar com o cotidiano dos estudantes, na diversidade de contextos e realidades. Por seu turno, o desenho curricular deveria ser planejado de maneira que os conteúdos dos componentes curriculares se articulassem entre si.

O Parecer das DCNEM No 15/1998, antes referido, manifestou a importância do Ensino Médio no processo de formação do aluno brasileiro, para o qual "converge o centro de gravidade do sistema educacional." (1998, p. 61). Esta importância decorreu da caracterização do Ensino Médio como detentor de uma identidade própria e como ciclo final da Educação Básica. O documento técnico sobre o estudo analítico do processo de implementação das Diretrizes Curriculares Nacionais para o Ensino Médio, de 2015 (BRASIL, MEC. Projeto UNESCO. Edital 7/2014, TOR 8/2014, DCNEM,

\footnotetext{
5 Para tratar da atualização das Diretrizes Curriculares Nacionais, para o Ensino Médio, foi criada, em janeiro de 2010, a Câmara de Educação Básica (CEB), integrante do CNE (Portaria CNE/CEB No 1/2010, recomposta pela Portaria CNE/CEB N²/2010).
}

Revista Exitus, Santarém/PA, Vol. 10, p. 01-32, e020030, 2020 
Projeto UNESCO/CNE 914BRZ1144), renovou a atenção acerca desse ciclo trienal.

As instâncias produtoras de regulações para o ensino, os sistemas aplicadores dos conjuntos de instruções e as agências avaliadoras de desempenho atuaram em conjunto para formação do estudante do Ensino Médio. As sucessivas transições demonstraram a necessidade de ajustes no sentido da formação do cidadão em idade escolar, do futuro trabalhador e da mentalidade crítica consoante aos saberes (áreas de conhecimentos propostas), à identidade e à alteridade.

\section{0 ensino médio em perspectiva - antes da bncc}

A educação escolar oficial brasileira se define em duas etapas. A primeira é a Educação Básica, constituída pela Educação Infantil e pelos ensinos Fundamental e Médio; a segunda, pelo Ensino Superior. As finalidades do Ensino Médio propedêutico definem-se pela preparação do educando à continuidade dos estudos, pela preparação básica para o trabalho e pelo exercício da cidadania. Os princípios pedagógicos estruturadores dos currículos desse ciclo são pautados pela identidade, diversidade, autonomia, interdisciplinaridade e contextualização.

De acordo com a Resolução No 3/1998, acima listada, o Ensino Médio organiza-se em três áreas de conhecimento: Linguagens, Códigos e suas Tecnologias; Ciências da Natureza, Matemática e suas Tecnologias; e Ciências Humanas e suas Tecnologias. Essa divisão por área de conhecimento escolar foi organizada para propiciar condições de um planejamento curricular na perspectiva interdisciplinar. E, ainda, justifica-se

[...] por assegurar uma educação de base científica e tecnológica, na qual conceito, aplicação e solução de problemas concretos são combinados com uma revisão dos componentes socioculturais orientados por uma visão epistemológica que concilie humanismo e tecnologia ou humanismo numa sociedade tecnológica (BRASIL, MEC. PCNEM, 2000, p. 19).

Visou-se, deste modo, a construção de projetos pedagógicos no âmbito de uma concepção transdisciplinar em que as linguagens, as 
ciências, as tecnologias, além dos conhecimentos históricos, sociológicos e filosóficos, fizessem parte de todas as ações do percurso escolar. Por seu turno, a Resolução $N^{\circ}$ 2/2012, de 30 de janeiro, reafirmou essa perspectiva interdisciplinar como metodologia de ensino, mas redefiniu a divisão por área de conhecimento da base comum do currículo: Linguagens, Matemática, Ciências Humanas e Ciências da Natureza. A área de Linguagens passou a constituir-se por: a) Língua Portuguesa; b) Língua Materna, para populações indígenas; c) Língua Estrangeira moderna; d) Arte, em suas diferentes linguagens: cênicas, plásticas e, obrigatoriamente, a musical; e) Educação Física.

Neste contexto da Resolução $N^{\circ}$ 2/2012, além da Base Comum, constituída por, no mínimo, 75\% da carga horária total, o Ensino Médio apresenta uma Parte Diversificada em conformidade às características regionais, locais, sociais, culturais e econômicas dos educandos, e proporciona os mesmos princípios pedagógicos do currículo comum. A finalidade foi assegurar uma formação básica para todas as escolas do país, tendo em vista a autonomia de escolhas de conteúdo entre os presentes na base obrigatória, e planejar projetos pedagógicos considerando o público e o contexto de cada região, sob o norte das diretrizes consolidadas em lei. Neste sentido, interdisciplinaridade e contextualização integraram-se como dimensões do currículo e asseguraram a transversalidade e a articulação dos saberes presentes nos componentes curriculares. Os desdobramentos das ações curriculares significam o alicerce para a formação da identidade de cada escola:

Cada escola/rede de ensino pode e deve buscar o diferencial que atenda as necessidades e características sociais, culturais, econômicas e a diversidade e os variados interesses e expectativas dos estudantes, possibilitando formatos diversos na organização curricular do Ensino Médio, garantindo sempre a simultaneidade das dimensões do trabalho, da ciência, da tecnologia e da cultura (BRASIL, MEC. Parecer CEB No 5/2011, p. 45).

A Resolução N 03/1998 e o Parecer das DCNEM/1998, supracitados, constituem os valores estéticos, políticos e éticos, como princípios 
fundamentais para nortear: as práticas administrativas e pedagógicas dos sistemas de ensino; o planejamento e a implementação de políticas educacionais e alocação de recursos; o planejamento da organização curricular. Esses valores foram organizados em três conceitos: a) estética da sensibilidade - centrada no estímulo à inventividade, à afetividade e à criação de identidades para o exercício da cidadania e para a valorização da qualidade, a sutileza, e das formas lúdicas, sem exclusão e intolerância; b) a política da igualdade - manifestação da equidade dos bens sociais e culturais, e do reconhecimento dos direitos humanos e dos deveres e direitos da cidadania; c) a ética da identidade - reconhecimento da identidade própria e do outro, fator complexo no âmbito escolar, tangente ao aluno, ao professor e à administração, pautada pela solidariedade, responsabilidade e reciprocidade. Por fim, a finalidade maior teorizada para esses valores foi a construção da autonomia e do juízo crítico, matrizes da formação do educando a experimentar desafios às suas capacidades e potencialidades. Esta perspectiva foi estendida para todos os documentos orientadores seguintes, constantes nos PCNEMs e nas OCNEM.

Os princípios pedagógicos da identidade, diversidade, autonomia, interdisciplinaridade e contextualização estruturaram o currículo do Ensino Médio à medida que se estabeleceu melhor adequação às necessidades dos alunos e do meio social de habitação e lugar da escola. Os projetos político-pedagógicos e os sistemas de ensino das escolas, segundo os pareceres derivados das DCNEM, ajustaram-se segundo os princípios: definição de um perfil próprio de atuação; articulação de parcerias com instituições públicas e privadas para firmar convênios, pois o Ensino Médio confere a preparação geral para o trabalho; promoção da diversificação dos conteúdos escolares, tanto da base comum quanto da parte diversificada, considerando as características dos alunos e as necessidades do meio; organização de propostas pedagógicas esquivas à burocracia e ao ritualismo das instâncias dos sistemas de ensino em que a escola e o seu corpo docente sejam os agentes principais.

O Parecer das DCNEM/1998 concluiu que os alunos do Ensino Médio 
manifestam maturidade escolar para utilizarem recursos de aprendizagem recorrendo à interdisciplinaridade e à contextualização. No primeiro caso, a elaboração de projetos de estudo, investigação e planos de intervenção favorecem a diferentes componentes curriculares se estruturarem em uma prática pedagógica transdisciplinar e contribuir para a execução das ações programadas. O estudo contextualizado, por seu turno, estimula o aluno a sair da condição passiva na situação de aprendizagem. Este procedimento didático confirmar-se na mobilização de competências cognitivas adquiridas dentro e fora da escola. Para esse parecer, a transposição didática dos conhecimentos para a prática, ou, de outro modo, a relação entre teoria e prática se concretiza em ações próximas aos familiares do aluno, considerando sua ambiência pessoal, social, econômica e cultural. Foi neste sentido que a alteração na LDB/2013 (Lei 12.796, de 04 de abril), no Artigo 26, estabeleceu a complementação curricular da Base Comum por outra diversificada, determinada pelas necessidades dos educandos.

O Ministério da Educação, tendo por desígnio intensificar a implementação da LDB, das DCNEM, dos PCNEMs e das OCNEM, emitiu a Portaria $N^{\circ}$ 971/2009, de 09 de outubro, a fim de instituir o Programa Ensino Médio Inovador (proEMI). Esse programa integrou as ações do Plano de Desenvolvimento da Educação (PDE) com o objetivo de reestruturar e fortalecer propostas metodológicas inovadoras no Ensino Médio não profissionalizante, instigando um redesenho curricular que atendesse às expectativas dos estudantes e às emergências sociais. O redesenho curricular (Projeto de Redesenho Curricular (PRC)) promoveu a educação científica e humanística ao propor como eixo comum a integração do trabalho, da ciência, da cultura e da tecnologia. A orientação pedagógica centrou-se na diversidade de contextos; e os conteúdos dos componentes curriculares foram orientados para articularem-se mutuamente. A reorganização curricular proposta para o Ensino Médio considerou a divisão dos conteúdos sistematizados nas quatro áreas de conhecimento, anteriormente mencionadas. 
Em 2011, a SEB publicou um documento técnico sobre a implementação, o acompanhamento e a avaliação do Programa Ensino Médio Inovador (proEMI/PDE). O documento foi elaborado a partir de dados obtidos pelo Censo Escolar 2010, do INEP, além de outros procedentes da Pesquisa Nacional por Amostra de Domicílios (PNAD/2009), da Síntese dos Indicadores Sociais de 2010 (SIS 2010), e do Instituto de Geografia e Estatística (IBGE). Em 2013, a SEB editou outro documento técnico sobre o proEMI. Este registro analisou o estudo de 2011 sobre a taxa de frequência dos estudantes, na faixa etária de 15 a 17 anos. Verificou-se que, apesar de $83,7 \%$ de frequência, a taxa de escolarização líquida ficou no nível de 51,6\%. Acerca das constatações deste quadro, o relatório de 2013 concluiu sobre a urgência de ampliação da universalização e do fortalecimento de políticas públicas para garantir o direito ao Ensino Médio de qualidade.

O Projeto de Redesenho Curricular propôs ações pedagógicas para a composição curricular que foram planificadas em disciplinas optativas, oficinas, seminários integrados e outras atividades interdisciplinares. As escolas que aderiram ao PRC organizaram ações a partir de macrocampos e de áreas de conhecimento consoantes às alternativas da equipe pedagógica e dos alunos. Dos oito macrocampos disponíveis, três instituíramse obrigatórios: Acompanhamento Pedagógico (Linguagens, Matemática, Ciências Humanas e Ciências da Natureza); Iniciação Científica e Pesquisa; Leitura e Letramento. Entre os demais, dois deveriam ser escolhidos, totalizando cinco macrocampos por escola: Línguas Estrangeiras; Cultura Corporal; Produção e Fruição das Artes; Comunicação, Cultura Digital e uso de Mídias; Participação Estudantil. Essas ações integraram paulatinamente os currículos, redundando em ampliação do tempo escolar do Ensino Médio. Essa ampliação do tempo do aluno na escola evoluiu para a perspectiva atual das Escolas de Ensino Médio de Tempo Integral (EMTI - Programa criado pela Medida Provisória No 746, de 22 de setembro de 2016, instituído pela Portaria $N^{\circ} 1.145$, de 10 de outubro de 2016).

Os pareceres divulgados sobre a implementação, a efetividade, e os resultados do Ensino Médio foram conclusivos em reconhecer problemas de 
diversa ordem. O Parecer das Diretrizes Curriculares Nacionais de 2011 (Parecer CNE/CEB No 5, de 05 de maio), por exemplo, concluiu que o último ciclo da educação básica ainda não superou o impasse sobre se forma o aluno para a educação superior ou para a inserção no mercado de trabalho. Desse modo, defendeu que as metas do Ensino Médio devem viabilizar

[...] a apropriação do conhecimento e desenvolvimento de métodos que permitam a organização do pensamento e das formas de compreensão das relações sociais e produtivas, que articule trabalho, ciência, tecnologia e cultura na perspectiva da emancipação humana (BRASIL, MEC. Parecer CEB No 5/2011, p. 29.).

Uma observação exógena a este parecer constata, entretanto, que inexiste ambiguidades na representação social do Ensino Médio Regular, pois, em que pese a implementação dos diversos projetos normativos e planos de fortalecimento dos projetos político-pedagógicos ensejados pelo MEC, incluindo a destinação de verbas, houve a supressão da formação básica para o trabalho, um dos fundamentos da LDB. A prática formativa do Ensino Médio tem se consolidado pela preparação dogmática com vistas ao ensino superior, sobretudo com a universalização do Exame Nacional do Ensino Médio (ENEM). O modelo de acesso à universidade aliado aos ganhos após a conclusão da faculdade agencia, sobremaneira, os jovens para a obtenção de um diploma de grau superior.

O mesmo Parecer das DCNEM/2011 constatou falhas entre as propostas do MEC e a execução delas pelas escolas, onde o ensino ainda estabelece prioridades ao conteúdo, indo de encontro aos princípios condenados pelas próprias diretrizes recentes da educação, que desaprova o acúmulo de conteúdos e os apelos à memorização, valorizados nas Diretrizes nacionais antigas:

Um dos problemas é o currículo que alunos são levados a estudar. É muito conteúdo para memorizar com pouco efeito prático. Os especialistas dizem que a escola fica distante da realidade dos alunos, o que torna o estudo pouco interessante, sem atrativos. (BRASIL, MEC. Projeto UNESCO. Edital 7/2014, TOR 8/2014, DCNEM, Projeto UNESCO/CNE 914BRZ1144, p. 06). 
A efetivação das metas encaminhadas pelas câmaras de ensino às secretarias de educação são prejudicadas pela carência de debates onde ocorre o ensino, as escolas:

\begin{abstract}
Mesmo considerando o tratamento dado ao trabalho didáticopedagógico, com as possibilidades de organização do Ensino Médio, tem-se a percepção que tal discussão não chegou às escolas, mantendo-se atenção extrema no tratamento de conteúdos sem a articulação com o contexto do estudante e com os demais componentes das áreas de conhecimento e sem aproximar-se das finalidades propostas para a etapa de ensino, constantes na LDB. (BRASIL, MEC. Projeto UNESCO. Edital 7/2014, TOR 8/2014, DCNEM, Projeto UNESCO/CNE 914BRZ1144, p. 16).
\end{abstract}

As escolas de Ensino Médio necessitam de ações institucionais articuladas a fim de que seu contexto educativo corresponda às regulações exigidas pelas políticas educacionais, considerando-se que ainda estão aquém das exigências almejadas pelo PNE, sobretudo pelas dificuldades de implementação globalizante de organização de saberes que reforce a importância da construção de projetos político-pedagógicos, nas escolas:

O primeiro fundamento para a formulação do projeto políticopedagógico de qualquer escola ou rede de ensino é a sua construção coletiva. O projeto político-pedagógico só existe de fato - não como um texto formal, mas como expressão viva de concepções, princípios, finalidades, objetivos e normas que orientam a comunidade escolar - se ele resultar do debate e reflexão do grupo que compõe a formação destes espaços (escola ou rede de ensino). Nesse contexto, identifica-se a necessidade do grupo comprometer-se com esse projeto e sentindo-se autores e sujeitos de seu desenvolvimento. (BRASIL, MEC. Projeto UNESCO. Edital 7/2014, TOR 8/2014, DCNEM, Projeto UNESCO/CNE 914BRZ1144, p. 37).

A contextualização e a diversidade, na construção do projeto pedagógico, foram somadas a atender a heterogeneidade de condições, interesses e aspirações dos estudantes. Esses fatores, vinculados aos conhecimentos da base comum, consolidaram a construção do currículo.

A BNCC/EF/EM (prevista na Constituição/1988, na LDB/1996, no PNE/2014) constitui a última referência do MEC para a construção de currículos. A Base reúne modelos de ensino obrigatórios a todos os níveis. $O$ objetivo da Base nacional é capacitar o aluno para atingir ao final da Educação Básica sustentação teórica e prática para o trabalho, 
competências para o prosseguimento dos estudos e preparação para ENEM. O Observatório do PNE, plataforma online coordenada pelo movimento Todos pela Educação, divulgou, em 03 de março de 2016, uma nota (OBSERVATÓRIO DO PNE. Secretários de Educação querem mudanças no Ensino Médio), informando que os secretários estaduais de Educação não conferiram, nos resultados preliminares da BNCC, mudanças estruturais no modelo do Ensino Médio. Neste sentido, o Conselho Nacional de Secretários de Educação (CONSED) anunciou, em 03 de março de 2016, uma carta, sugerindo alterações no documento em análise. Essa carta foi apresentada ao Conselho Nacional de Educação. Para os secretários estaduais, o novo modelo deveria permitir trajetórias alternativas aos estudantes; que Ihes dessem a oportunidade de escolher uma formação para o ensino técnico, tecnológico ou superior acadêmico, debate ausente nas primeiras versões da BNCC - A demanda dos secretários estaduais foi atendida pela Resolução MEC N 3, de 21 de novembro de 2018. Esta resolução institui, no Art. 11, os seguintes percursos formativos aos estudantes do Ensino Médio: linguagens e suas tecnologias; matemática e suas tecnologias; ciências da natureza e suas tecnologias; ciências humanas e sociais aplicadas. O CONSED apontou ainda dois problemas: a) a disparidade entre os objetivos da Base Nacional relativamente à formação do aluno no Ensino Médio para o mundo do trabalho e a proposta curricular apresentada - que não proporciona o alcance para esse fim; b) e o excesso de componentes curriculares e de conteúdos propostos.

Em decorrência dos muitos debates suscitados, O MEC redefiniu a estrutura da carga horária letiva e os percursos curriculares para o Ensino Médio, além de outros direcionamentos pedagógicos a serem praticadas a partir da promulgação da BNCC. A antiga Resolução CEB № 3/1998, supra referida, determinava $75 \%$ do tempo mínimo de 2.400 horas, ou seja, de 800 horas por ano. E o currículo dividia-se em uma parte comum, com maior carga de horas, e outra diversificada. A nova determinação ampliou esse tempo a dilatar-se progressivamente, devendo atingir, até 2022, o calendário constituído por 3.000 (três mil) horas, e a carga horária anual total devendo 
ser ampliada progressivamente para 1.400 (um mil e quatrocentas) horas (BRASIL, RESOLUÇÃO MEC Nº 3, 2018) - o aumento da carga horária letiva foi já proposta pelo proEMI/2013. Dessa carga horária, $60 \%$ será preenchida por conteúdo obrigatório, ficando $40 \%$ composta por conteúdos sob escolhas das escolas. Estas, por sua vez, deverão oferecer à comunidade escolar pelo menos um entre os cinco itinerários formativos, segundo a escolha dos alunos: linguagens e suas tecnologias, matemática e suas tecnologias, ciências da natureza e suas tecnologias, ciências humanas e sociais aplicadas, formação técnica e profissional ${ }^{6}$. Essa nova diretriz curricular pretende implementar maior flexibilização do projeto político-pedagógico e diminuir a evasão escolar.

Tangente à padronização do ensino, na BNCC, cada ano cumprirá determinados conteúdos selecionados com 0 fito de atingir objetivos também determinados pelas estratégias pedagógicas. No componente curricular Língua Portuguesa, por exemplo, a cada ano escolar o professor se deparará com os objetivos estabelecidos a serem alcançados pelo aluno. Este planejamento direcionará as competências dos egressos quanto ao uso da língua materna e ao conhecimento das suas literaturas, perspectiva didática que melhor estruturará o ensino-aprendizagem em face dos documentos anteriores, cujas diretrizes e pareceres legais pouco sistematizaram a aplicação dos conteúdos, gerando problemas no cumprimento dos currículos. Os PCNEMs e as OCNEM apresentavam mais sugestões do que medidas de execução de didáticas e de conteúdos. Ou seja, faltou um pragmatismo que aos poucos a BNCC deverá implementar.

As ações do MEC, para o Ensino Médio, antes da BNCC, visaram efetivar uma visão sistêmica segundo a compreensão do relatório do Projeto UNESCO/CNE/2014. Trata-se do reconhecimento das conexões intrínsecas entre Educação Básica e Superior, e entre formação humana, científica, cultural e profissionalização. A partir dessas vinculações, este relatório concluiu que se devam promover políticas públicas intensivas para a

\footnotetext{
6 O Novo Ensino Médio determina cinco áreas de conhecimento: Matemática e suas tecnologias, Linguagens e suas tecnologias, Ciências da natureza e suas tecnologias, Ciências humanas e sociais aplicadas, e Ensino religioso.
} 
educação:

Para alcançar o pleno desenvolvimento, o Brasil precisa investir [...] na ampliação de sua capacidade tecnológica e na formação de profissionais de nível médio e superior. [...]. Sem uma sólida expansão do Ensino Médio com qualidade, [...] não se conseguirá que nossas universidades e centros tecnológicos atinjam o grau de excelência necessário para que o País dê o grande salto para o futuro. (BRASIL, MEC. Projeto UNESCO. Edital 7/2014, TOR 8/2014, DCNEM, Projeto UNESCO/CNE 914BRZ1144, p. 09).

O Parecer das DCNEM/1998 denunciou reiteradamente que entre as propostas para uma educação de qualidade deve-se enfatizar a preparação das competências do docente, pois o despreparo desse profissional acusa um embargo para a implementação das diretrizes curriculares para o Ensino Médio. Por seu lado, as conclusões do Projeto UNESCO/CNE 2014 registraram, também, distâncias entre as câmaras de ensino e o espaço de execução das propostas curriculares: a sala de aula. Em suma, o corpo docente da escola não está sendo preparado para assumir adequadamente a educação básica. Este parecer das DCNEM/1998 já acusava o problema da formação do professor, sendo "um peso que deve ser transferido às instituições de Ensino Superior, para que o considerem [...] as responsabilidades com o País e com a Educação Básica [...]." (BRASIL, CONSELHO NACIONAL DE EDUCAÇÃO, 2001, p. 96). Por fim, este mesmo parecer reitera as competências dos protagonistas formadores dos futuros profissionais: "Das instituições de Ensino Superior, espera-se que sejam parceiras no enfrentamento do desafio e na solução, não apenas na denúncia do problema." (BRASIL, CONSELHO NACIONAL DE EDUCAÇÃO, 2001, p. 96).

Os procedimentos adotados para a educação no Ensino Médio, consoante os documentos acima apresentados, estabeleceram normativas gerais para a consolidação dos objetivos almejados pelos currículos a partir das áreas de conhecimento. Para complementar as Diretrizes Curriculares (DCNEM), na área de Linguagens, por exemplo, foram redigidos os Parâmetros Curriculares Nacionais para o Ensino Médio e as Orientações Curriculares para o Ensino Médio com o encargo de explicitar cada área 
conhecimento. Entretanto, as abordagens divulgadas destes documentos apresentaram generalidades e aproximações, sem de fato materializarem um programa em que a base comum apresentasse conteúdos, metodologias e objetivos em uma planilha mais detalhada e exequível.

\section{Tentativas de educação literária nos Parâmetros e nas Orientações curriculares nacionais}

Os PCNEM e as OCNEM, da área de Linguagens, códigos e suas tecnologias, redigidos sob regulamentação das DCNEM/1998, apresentam um conjunto de instruções pedagógicas, sem força normativa, concebidos para auxiliar os professores a partir de propostas e sugestões metodológicas, visando delimitar conteúdos e definir conceitos, competências e habilidades, no processo ensino-aprendizagem, além da revisão de projetos pedagógicos com a perspectiva do aperfeiçoamento contínuo dos currículos.

Os PCNEM/1999 e os PCNEM+ 2002 encerram proposições de caráter indicativo e interpretativo. Neste caso, os PCNEM/1999 propõem "a interatividade, o diálogo, a construção de significados na, pela e com a linguagem." (p. 04). Os dois Parâmetros recomendam o ensino a partir do conhecimento contextualizado e da interdisciplinaridade, tendo em vista a diversidade geográfica, econômica e cultural do país, agenciando o raciocínio e a capacidade de aprender. A proposta desses documentos centrou-se principalmente no ensino articulado entre os componentes da área de Linguagens - Língua Portuguesa, Artes, Educação Física, Língua Estrangeira Moderna e Tecnologias da Informação -, e desta área com as outras duas, Ciências Humanas e suas Tecnologias e Ciências da Natureza, Matemática e suas Tecnologias.

Os PCNEM/1999 apresentaram orientações curriculares aquém das necessidades do ensino da Língua Portuguesa e das suas literaturas. Eles explicitaram os sentidos destes conteúdos, relevando suas competências e habilidades, bem como seus eixos norteadores, na tríade: a) Representação e comunicação; b) Investigação e compreensão; c) Contextualização 
sociocultural. Embora esse documento tenha idealizado uma realização interdisciplinar e contextual, não agenciou metodologias para execução dos conteúdos. As indicações foram genéricas e a parte prática limitou-se a teorizações: "Podemos assim falar em linguagens que se confrontam, nas práticas sociais e na história, e fazem com que a circulação de sentidos produza formas sensoriais e cognitivas diferenciadas." (BRASIL, PCNEM,1999, 2015. p. 06). Este outro excerto manifesta exemplarmente o que se deveria traduzir por soluções e não inviabilizar propostas, pois não há detalhamento de sugestões, atividades, metodologias e competências a alcançar:

\begin{abstract}
No campo dos sistemas de linguagem, podemos delimitar a linguagem verbal e não-verbal e seus cruzamentos verbo-visuais, audiovisuais, áudio-verbo-visuais etc. A estrutura simbólica da comunicação visual e/ou gestual como da verbal constitui sistemas arbitrários de sentido e comunicação. A organização do espaço social, as ações dos agentes coletivos, normas, os costumes, rituais e comportamentos institucionais influem e são influenciados na e pela linguagem, que se mostra produto e produtora da cultura e da comunicação social (p. 06).
\end{abstract}

Em outra parte, este documento de 1999 apontou as competências e habilidades gerais a serem alcançadas pelos alunos, mas sem apresentar os conteúdos específicos e as suas respectivas metas. Um exemplo da inobservância relativa aos conteúdos pertinentes ao ensino do componente Língua Portuguesa, surpreendeu-se na transcrição abaixo:

Ao ler este texto, muitos educadores poderão perguntar onde está a literatura, a gramática, a produção do texto escrito, as normas. Os conteúdos tradicionais foram incorporados por uma perspectiva maior, que é a linguagem, entendida como um espaço dialógico, em que os locutores se comunicam. Nesse sentido, todo conteúdo tem seu espaço de estudo, desde que possa colaborar para a objetivação das competências em questão (p. 23).

O ensino da Língua Portuguesa/Literatura ajustou-se aos três eixos estruturadores citados no sentido de desenvolvê-los e tomá-los como guias na descrição das competências e habilidades. No segmento "Investigação e Compreensão", relativamente à abordagem da educação literária, localizou-se carência de sugestões metodológicas, e apenas uma breve indicação sobre atividades a serem cumpridas: "Recuperar, pelo estudo do 
texto literário, as instituídas de construção do imaginário coletivo, o patrimônio representativo da cultura e as classificações preservadas e divulgadas, no eixo temporal e espacial." (BRASIL, PCNEM, 1999, 2015. p. 14).

Os PCNEM+/2002 aprofundaram as orientações genéricas dos Parâmetros de 1999, sobre a área de Linguagens, códigos e suas tecnologias. Entretanto, esse documento de referência apresentou uma redação extensa, com abordagens pouco acessiveis aos professores com limitada formação acadêmica em Língua Portuguesa/Literatura, além de um discurso municiado de reflexões sobre a relação entre os conteúdos internos da área de Linguagens, e desta com outras áreas - interdisciplinaridade e transdiciplinaridade. Os três eixos de competências norteadores para a Língua Portuguesa/Literatura, definidos nos PCNEM/1999 (Representação e Comunicação, Investigação e Compreensão, Contextualização Sociocultural), são conservados nos PCNEM+/2002. Para cada um desses eixos, foram organizados conceitos estruturantes, competências e habilidades relacionados a conceitos. Desse modo, o texto do documento apresenta muitas definições e apontamentos, sem o pragmatismo adequado para a compreensão didática pelo professor. Para aclarar, o eixo Contextualização Sociocultural compreende dez conceitos e sete habilidades e competências. Além disso, os conceitos gerais da área desdobram-se em competências e habilidades em grande quantidade para o eixo Investigação e Compreensão, foram selecionados sete conceitos e seis competências e habilidades, sendo todos detalhados, no documento, por exemplo.

Por fim, a organização dos conteúdos da Língua Portuguesa/Literatura ajustou-se segundo temas estruturadores, sendo que, estes, por seu turno, desmembram-se em unidades temáticas. Esses Parâmetros+/2002 sugeriram quatro grandes temas: 1. Usos da língua; 2. Diálogo entre textos: um exercício de leitura; 3. Ensino de gramática: algumas reflexões; 4. O texto como representação do imaginário e a construção do imaginário cultural. Cada um desses temas apresentou os três eixos supra referidos nos quais estão inscritas as competências gerais. Às quatro unidades temáticas 
relacionadas, correspondem competências e habilidades específicas.

O domínio Literatura localiza-se no quarto grande tema, constante nas Competências Gerais e nas Competências Específicas. No primeiro caso, relacionado ao eixo da Representação e Comunicação, com as habilidades e competências transcritas dos PCNEM/1999, conforme transcrição acima, e, no segundo, relacionado às unidades temáticas, com três habilidades/competências: "recuperar, pelo estudo do texto literário, as formas instituídas de construção do imaginário coletivo; analisar diferentes abordagens de um mesmo tema; resgatar usos literários das tradições populares." (BRASIL, PCNEM+, 2002, p. 74).

Tendo em vista a grande quantidade dos conceitos e das competências/habilidades do componente curricular Língua Portuguesa para a implementação dos ideários das DCNEM e dos PCNEMs, elege-se o comentário de dois tópicos, dos PCNEM+/2002:

a) A quantidade e a complexidade de conceitos, bem como as respectivas competências e habilidades definidas, exigem debates e reflexões por parte de especialistas sobre o fenômeno das linguagens e suas articulações com outras áreas de conhecimento para melhor entendimento das ideias dispostas. Ou seja, as informações dos PCNEM+/2002 exigem acurada formação do docente para compreendê-las e, a partir delas, estruturar unidades de trabalho. No domínio do conceito sintaxe, por exemplo, observa-se: "como arranjo, combinação convencionalmente definida, é indispensável para entender a natureza da disciplina, seus recursos fundamentais, a razão de sua inserção em determinada área e suas interfaces com as demais disciplinas." (BRASIL, PCNEM+, 2002, p. 43).

b) Constatou-se a insuficiente importância destinada ao texto literário, no cerne dos ensinos da Língua Portuguesa e da Literatura. A ênfase incidiu sobre o texto, oral e escrito, e verticalizou paradigmas de ensino dirigido a estudos da linguagem sem atinar-se para maior contribuição do texto literário como um corpus imprescindível à aquisição da competência linguística. Também, não se divisou, no conjunto das proposições, encaminhamentos para a formação do leitor e o conhecimento intrínseco 
da obra literária, além do reconhecimento desta como bem imaterial e patrimônio nacional singular.

Do exposto, conclui-se, resumindo, que um dos maiores entraves para o baixo êxito na implementação das orientações dos Parâmetros+/2002 redunda na deficiente capacidade do professor (geralmente sem formação continuada) para abstrair as ideias das muitas informações neles contidas e colocá-las em prática. Entretanto, os autores desses Parâmetros apostam na argúcia intelectual do docente:

É fundamental, por isso, que o professor conheça os conceitos que estruturam sua disciplina e a relação destes com os conceitos estruturantes das demais disciplinas da sua área, a fim de conduzir o ensino de forma que o aluno possa estabelecer as sínteses necessárias para a aquisição e o desenvolvimento das competências gerais previstas para a área (2002, p. 27).

À aprendizagem no Ensino Médio, de acordo com as DCNEM/1998, cumpre-se oferecer uma formação básica para o estudante no sentido de propiciar a continuidade dos estudos e de inseri-lo no mundo do trabalho. Assim, diligenciar uma formação integral do jovem para o exercício da cidadania a partir de um currículo disponível à multiplicidade de contextos escolares. É neste sentido que emana dos parâmetros curriculares o pensamento de formação globalizante. Desse modo, todas as áreas de conhecimento devem ser dinamizadas pela interdisciplinaridade, sendo esta uma necessidade advinda do contexto e da diversidade cultural. "Interdisciplinaridade", "contexto" e "diversidade" são palavras-chave do currículo para se investigar e produzir conhecimentos. A base comum e a parte diversificada se associam relativamente à formação do estudante a fim de desenvolver competências entre as áreas de ensino.

A preparação interdisciplinar e contextual do Ensino Médio, ditada pelas normatizações curriculares, é cobrada pelo Exame Nacional do Ensino Médio:

[...] OS PCNEM explicitam três conjuntos de competências: comunicar e representar, investigar e compreender, assim como contextualizar social ou historicamente os conhecimentos. Por sua vez, de forma semelhante mas não idêntica, o Enem aponta cinco 
competências gerais: dominar diferentes linguagens, desde idiomas até representações matemáticas e artísticas; compreender processos, sejam eles sociais, naturais, culturais ou tecnológicos; diagnosticar e enfrentar problemas reais; construir argumentações; e elaborar proposições solidárias. Tanto nos Parâmetros Curriculares Nacionais do Ensino Médio, como no Enem, relacionam-se as competências a um número bem maior de habilidades (BRASIL, PCNEM+, 2002, p. 15).

As provas do ENEM de 2015, da área de Linguagens, códigos e suas tecnologias, exigiram primordialmente do aluno capacidades de interpretação e de estabelecimento de relações entre conhecimentos de Literatura, História, Filosofia, Antropologia, Sociologia/Ações afirmativas/Cidadania, Língua Portuguesa, Artes e Tecnologias da informação. A cobrança por saberes especificamente técnicos sobre a Gramática ou a Literatura foi de somenos importância; e as questões relacionadas às humanidades apareceram de modo interdisciplinar, em que se misturaram temas da atualidade e do cotidiano. Por sua vez, as questões atinentes à leitura de obras literárias exigiram apenas a prática interpretativa, porquanto não ocorre a exigência das leituras obrigatórias.

\subsection{As orientações curriculares e a formação do leitor}

No âmbito do componente curricular Língua Portuguesa, relativamente ao domínio da Literatura e da formação do leitor e das suas respectivas competências (interpretações de textos e de contextos, produção escrita e oralidade, em diversos ambientes), falta melhor aparelhamento de ferramentas para acompanhar e avaliar os planejamentos curriculares sobre leituras orientadas em sala de aula ou extraclasse, no Ensino Médio. A formação de leitores ainda é um dos problemas mais graves no domínio da Língua Portuguesa, apesar dos investimentos do MEC, que desenvolve, desde 2007, o Programa Nacional Biblioteca da Escola (PNBE), com a distribuição de acervos de obras literárias, de pesquisa e de referência. Esse investimento objetiva promover, entre estudantes e professores, a prática educativa da leitura literária, e a ampliação de conhecimentos literários por intermédio dos textos narrativos, poéticos e dramáticos. Ainda, como apoio para diminuir 
evasões e guarnecer suportes didáticos, o MEC, desde 2004, desenvolve o Programa Nacional do Livro Didático para o Ensino Médio (PNLEM). Alunos e professores da rede pública de todo o país passaram a receber gratuitamente, desde então, o livro didático de Língua Portuguesa/Literatura.

As OCNEM apresentaram o problema da continuidade formativa do aluno-leitor iniciada no Ensino Fundamental e complementada no Ensino Médio. Este documento cientificou que nos anos finais do Ensino Fundamental $\left(6^{\circ}\right.$ ao $9^{\circ}$ ano), a sistematização é menos rigorosa relativamente a escolhas de obras. Neste período, as escolas direcionam a seleção de textos para a denominada literatura infanto-juvenil e para as pertencentes ao cânone, validadas pela tradição escolar. Neste âmbito, os adolescentes constroem um repertório de leituras voltado para o que esse documento classifica por "escolhas anárquicas" (2006, p. 61), pois rejeitam o cânone e optam por livres experiências de leituras monitoradas por controles externos às didáticas de ensino e sujeitas às leis de mercado. Embora as escolhas sejam aleatórias, esses alunos têm contato direto com algumas obras literárias na escola, quer sejam fragmentadas ou resumidas. As OCNEM concluem que os gêneros literários experimentados pelo aluno do Fundamental, dentro da sala de aula e fora dela, garantem um alicerce para o ensino da Literatura e contribuem para o planejamento da reorientação da leitura, no Ensino Médio.

As OCNEM idealizam que o estudante nesta fase esteja mais preparado intelectualmente, portanto mais apto a desenvolver suas habilidades de leitura. Entretanto, o processo iniciado no Ensino Fundamental "se perde em objetivos pragmáticos, formulados, sobretudo, nos manuais didáticos, que, mais para o mal que para $\bigcirc$ bem, vêm tradicionalmente cumprindo o papel de referência curricular para esse nível da escolaridade." (BRASIL, OCNEM, 2006, p. 64). De todo modo, o contato direto com a obra literária permanece insatisfatório para a formação do leitor, sendo o livro didático apenas um suporte para o ensino a enfatizar abordagens metatextuais e a fragmentar a história literária e a crítica textual. 
Professores da rede pública estadual de ensino, em entrevistas, executadas pelo autor deste texto, informaram que docentes do componente Língua Portuguesa, Ensino Médio, recebem orientação para indicar três livros didáticos, dos quais um deve ser selecionado para escola. Mas as escolhas não são geralmente atendidas, causando, em alguns casos, o abandono desses manuais fora da listagem apresentada. Os professores denunciam, neste caso, interesses externos aos da comunidade escolar, pois suas seleções são ignoradas. Este desajuste compromete os objetivos do PNLEM. As OCNEM recomendam ao professor, sendo um experiente leitor, compartilhar suas estratégias para a seleção das obras e das suas respectivas leituras integrais, porquanto no planejamento do componente curricular ele tem prerrogativa para isso. Os PCNEM, as OCNEM e a BNCC não estabelecem lista de leituras obrigatórias. Neste sentido, "fica-nos uma questão de natureza complexa, pois pressupõe ordenação e valores: que livros escolher?" (BRASIL, OCNEM, 2006, p. 65).

Neste sentido, projetando-se um paralelo entre os principais textos orientadores para Língua Portuguesa tangente à educação literária nos ensinos Médio, em Portugal, e Secundário, no Brasil, conferem-se estratégias diversas de acesso ao texto literário. No caso nacional, a educação literária ocorre pelo livro didático e pelas escolhas de obras ocasionais do professor, sob reduzida carga horária para o cumprimento da leitura; no segundo, há uma sistematização bibliográfica direcionada a cada ano do Secundário, proporcionando amplo acesso ao livro (PORTUGAL, Ministério da Educação e Ciência. Programa e Metas Curriculares de Português - Ensino Secundário). Além disso, embora a perspectiva sobre a Literatura e a Língua Portuguesa nesses ensinos conservem as concepções de literacia (Portugal) e letramento (Brasil), ainda não houve uma instrução que esclarecesse a relevância do texto literário para o ensino da língua materna, nos documentos nacionais, ao contrário do que ocorre nos do país lusitano.

O problema da leitura persiste em razão de o texto literário constar como uma prática artística secundarizada e pela ausência de um contexto específico para a formação literária no âmbito da Língua Portuguesa, nas 
escolas nacionais. O ensino lusitano, por seu turno, privilegia a educação literária, sendo um dos domínios da disciplina Língua Portuguesa, imprimindo a valorização da dimensão estética do texto literário e realçando as contribuições imprescindíveis da Literatura para o aprendizado da língua materna, entre outros fatores de valorização do texto literário.

\section{CONCLUSÃO}

A construção dos currículos e projetos pedagógicos, para a área de Linguagens, deriva dos documentos complementares à LDB/1996 e às diretrizes curriculares/98, referências implementadas pelas secretarias estaduais de educação. As orientações legais não são consumadas plenamente pela falta de políticas públicas educacionais efetivas. Um dos modos de se admitir os problemas relacionados à aprendizagem, identificase nos resultados de processos avaliativos nacionais (SAEB e ENADE). Ainda, na falta de um programa pedagógico de ajuste entre o currículo do Ensino Médio e os cursos superiores de lincenciatura.

Entre os entraves à implementação das diretrizes idealizadas pelo MEC para o Ensino Médio e fraco desempenho dos alunos, apontam-se:

a) Desajuste entre os documentos de referência para a construção curricular (orientação interdisciplinar e transdisciplinar) e a formação recebida pelo professor, na universidade (não interdisciplinar). Nas faculdades de Letras, o ensino articulado entre os componentes da área, e, destes, com outras áreas, não está alinhado às proposições do MEC. Não é comum os programas stricto sensu em Letras Língua Portugesa promoverem cursos tendo em vista a interdisciplinaridade fomentada pelas orientações nacionais, para o Ensino Médio.

b) O currículo: o excesso de componentes curriculares comprometeu as diretrizes da LDB sobre a formação para estudos posteriores e para o mundo do trabalho. A quantidade desses componentes fomentou a evasão escolar, enquanto a falta da opção por um percurso formativo prejudicou também a escolha por cursos superiores, pelos estudantes. A formação curricular tem priorizado sobretudo a capacitação para o ENEM. 
c) Os documentos complementares para fundamentar a construção dos currículos são extensos e apontam norteamentos sem finalidades precisas para a organização dos conteúdos. Eles também não sugerem metodologias, conforme observado nos PCNEMs e nas OCNEM (para a educação literária/formação do leitor). Além disso, para melhor compreensão dos conceitos, exigem preparação intelectual acurada dos seus leitores.

d) Essas referências curriculares não chegaram a todas as escolas e/ou nelas não aconteceram estudos e debates acerca dessas orientações.

e) Não houve alinhamento curricular entre o Ensino Médio e a matriz curricular das licenciaturas em Língua Portuguesa.

Entende-se que um dos fatores que desafiou $o$ ensino e a aprendizagem do conteúdo Literatura esteve vinculado à falta de integração dos currículos do ensino universitário com as licenciaturas e com a educação básica, como se verifica empiricamente nas práticas docentes. Outro fator determinante para o insucesso escolar dos alunos atrela-se à ausência de fomento, pelo sistema educacional, à formação dos docentes estudos dos documentos de referência do MEC, pós-graduações, e renovações de projetos pedagógicos.

\section{REFERÊNCIAS}

BRASIL. Ministério da Educação. Secretaria de Educação Média e Tecnológica. Parâmetros Curriculares Nacionais - Ensino Médio - Linguagens, Códigos e suas Tecnologias. Brasília: MEC/SEMTEC, 1999.

BRASIL. Secretaria de Educação Média e Tecnológica. PCN+ Ensino Médio: Orientações Educacionais complementares aos Parâmetros Curriculares Nacionais. Linguagens, códigos e suas tecnologias. Brasília: Ministério da Educação/Secretaria de Educação Média e Tecnológica, 2002.

BRASIL. Ministério da Educação e Desporto. Orientações Curriculares para o Ensino Médio - Linguagens, Códigos e suas Tecnologias. Brasília: MEC/Secretaria de Educação Básica, 2006.

BRASIL Ministério da Educação. Projeto UNESCO, Edital 7/2014, TOR 8/2014, Diretrizes Curriculares Nacionais para o Ensino Médio, no âmbito do Projeto UNESCO/CNE 914BRZ1144. 
BRASIL. Base Nacional Comum Curricular - segunda versão revista. Ministério da Educação, 2016.

BRASIL. Ministério da Educação LEI N 12.796, de 4 de abril de 2013 - altera a Lei No 9.934, de 20 de dezembro de 1996, que estabelece as diretrizes e bases da educação nacional. Disponível em:

<http://www.planalto.gov.br/ccivil_03/_ato2011-2014/2013/lei/l12796.htm>. Acesso em: 20 set. 2018.

BRASIL. Ministério da Educação e Cultura. Lei de Diretrizes e Bases da Educação Nacional, Lei № 9.394, de 20 de dezembro de 1996. Estabelece as diretrizes e bases da educação nacional. Disponível em:

http://www.planalto.gov.br/ccivil_03/Leis/L9394.htm. Acesso em 20 out. 2018.

BRASIL. Ministério da Educação e Cultura. Resolução CNE/CEB RE N 3, de 26 de junho de 1998. Institui as diretrizes curriculares para o Ensino Médio. Disponível em: http://portal.mec.gov.br/seb/arquivos/pdf/res0398.pdf > Acesso em: 20 out. 2018.

BRASIL. Ministério da Educação e Cultura. Lei de Diretrizes e Bases da Educação Lei No 12.796, de 4 de abril de 2013. Altera a Lei $N^{0} 9.394$, de 20 de dezembro de 1996, que estabelece as diretrizes e bases da educação profissional, para dispor sobre a formação dos profissionais da educação e dar outras providências. Disponível em:<http://www.planalto.gov.br/ccivil_03/_ato201 12014/2013/lei/l12796.htm>. Acesso em: 15 jan. 2019.

BRASIL Ministério da Educação e Cultura. Parecer CEB N 15, de 01 de janeiro de 1998. Disponível em:

<http://portal.mec.gov.br/cne/arquivos/pdf/PCB15_1998.pdf>. Acesso em: 15 jan. 2019.

BRASIL Portaria N 971, de 9 de outubro de 2009. Institui o Programa Ensino Médio Inovador (ProEMI). Disponível em:

http://pactoensinomedio.mec.gov.br/images/pdf/port_971_09102009.pdf. Acesso em 15 jan. 2019.

BRASIL Resolução CNE/CEB RE N 4, de 13 de julho de 2010. Define Diretrizes Curriculares Nacionais Gerais para a Educação Básica. Disponível em: < http://portal.mec.gov.br/dmdocuments/rceb004_10.pdf>. Acesso em: 15 jan. 2019.

BRASIL Programa Ensino Médio Inovador. Documento Orientador 2011.

Disponível em:

<http://portal.mec.gov.br/index.php?option=com_docman\&view=download 
\&alias=9607-documentoorientador-proemi\&ltemid=30192>. Acesso em: 20 jan. 2019.

OBSERVATÓRIO DO PNE. Secretários de Educação querem mudanças no Ensino Médio. Disponível em:

<http://www.observatoriodopne.org.br/noticias/secretarios-estaduais-deeducacao-querem-mudancas-no-ensino-medio>. Acesso em: 21 jan. 2019.

PORTUGAL. Ministério da Educação e Ciência. Programa e Metas

Curriculares de Português - Ensino Secundário. Disponível em:

http://www.dge.mec.pt/sites/default/files/Secundario/Documentos/Docume ntos_Disciplinas_novo/progra_metas_curriculares_portugues_secundario.pdf $>$ Acesso em: 25 ago. 2019.

BRASIL. Ministério da Educação, RESOLUÇÃO MEC N 3, de 21 de novembro de 2018. Disponível em: < http://portal.mec.gov.br/docman/novembro-2018pdf/102481-rceb003-18/file>. Acesso em: 25 ago. 2019.

Recebido em: 06 de novembro de 2019

Aprovado em: 13 de janeiro de 2020 